www.jmscr.igmpublication.org

Index Copernicus Value: 79.54

ISSN (e)-2347-176x ISSN (p) 2455-0450

crossref DOI: https://dx.doi.org/10.18535/jmscr/v7i5.47

\title{
Clinical Spectrum of Fever Cases in Correlation with Hemato-Biochemical Parameters- An Experience from a North Indian Hospital
}

\author{
Authors \\ Dr Ankur Malhotra ${ }^{1}$, Dr Viney Sambyal ${ }^{2 *}$, Dr Sanjay Sharma ${ }^{3}$ \\ ${ }^{1}$ Senior Resident Medicine, Post-Graduate Department of Medicine, GMC Jammu \\ ${ }^{2}$ Lecturer Medicine, Post-Graduate Department of Medicine, GMC Jammu \\ ${ }^{3}$ Lecturer Medicine, Post-Graduate Department of Medicine, GMC Jammu \\ *Corresponding Author \\ Dr Viney Sambyal \\ Email: vineysambyal@gmail.com, Ph- 9419152854
}

\begin{abstract}
Introduction: The purpose of this study is to study the clinical spectrum of fever cases, outline the hematobiochemical and serological parameters and delineate a syndromic approach to tropical infections in a Tertiary hospital of North India.

Methods: The study included 926 cases of fever admitted to our hospital, GMC Jammu, in medical wards over a period of six months and corelating their clinical manifestations with the lab parameters (hematological, biochemical, serology) and imaging modalities.

Results: Out of 926 cases admitted with fever, 78 (8.4\%) cases were undifferentiated viral fever, 140 (15.2\%) were enteric fever, 85(9.2\%) were dengue, 126(13.6\%) were malaria, 28(3\%) of hepatitis A and $26(2.8 \%)$ of hepatitis E, 14(1.5\%) of varicella, 86(9.4\%) of pneumonia and 81(8.7\%) of UTI.45(4.9\%) liver abscess were reported along with 186(20.1\%) cases of Rickettsial Fever, $0.2 \%$ of leptospirosis and $0.6 \%$ of Tuberculosis .

Conclusion: In our study, predominantly younger population(<55 years) was most commonly affected. The most common etiology was found to be Rickettsial Fever followed by Enteric Fever and Malaria. This upholds the necessity for better health awareness, early transport and presentation along with better diagnostic tools at primary health care facilities.
\end{abstract}

Keywords: Hepatitis, dengue fever, Enteric fever, Rickettsial Fever, Malaria.

\section{Introduction}

Fever without diagnosis is an unpleasant situation which neither the patient nor the treating physician would like to be in. However this is the single most baffling problem faced by every physician in their daily practice. Fever is a common reason for seeking healthcare in low-and middle-income countries ${ }^{[1]}$. Among patients with febrile illness requiring admission case fatality ratios are high, sometimes exceeding $20 \%^{[2-6]}$. To describe epidemiologic patterns and to identify data gaps in our understanding of severe febrile illness in low resource areas, we sought to systematically review prospective hospital based study of the etiology of febrile illness. Every year different parts of India are hit by seasonal fevers 
especially during the monsoon and post monsoon period between June to September as stated other studies $^{[7,8]}$. Acute undifferentiated febrile illness can be differentiated from Fever of unknown origin by fever duration, and progression as described by Phuong et al. ${ }^{[9]}$.

\section{Methodology}

A cross-sectional study was conducted over a period of 6 months from 1 June 2018 to 1 Dec 2018. All 15 to 85 years aged admitted cases with history of fever over 38.3 degrees $\mathrm{C}$ for $<3$ weeks of duration without any specific localizing signs or symptoms were enrolled for the study. All critically ill patients requiring direct admission to ICU, cases of localized infection like abdominal infections, meningitis etc., patients of severe sepsis with septic shock, haematological malignancies, autoimmune disorders, those on immunosuppressant, fever $>3$ weeks' time (PUO) were excluded from the study. Following information was retrieved: demographic data including age, sex and clinical hospitalization data including rash, vomiting, headache, joint pain, diarrhoea. Relevant biochemical, haematological and serological data were also retrieved for eg. Dengue NS1 Ag/IgM antibody, malarial parasite slide/card, Rickettsial serology, typhidot assay. Laboratory results were interpreted as per standard diagnostic criteria's for different etiologies.

Data thus collected were incorporated in to Microsoft excel sheet and analysed using IBM SPSS version 20 software (trial version).

\section{Results}

A total of 1560 patients were admitted during study period of 6 months. Out of these, 926 were enrolled in study and 634 were excluded as per exclusion criteria. Of total 926 patients, males (58.3\%) were more commonly affected in comparison to females (41.7\%). (Table 1) Majority of the patients were young, in their second, third and fourth decades of life with $57.9 \%$ of patients between 15 to 45 years of age.
$2.8 \%$ of patients were above age of 86 years. (Table 2)

Symptoms associated with fever were vomiting (44.3\%), malaise (62.6\%), joint pain (30.7\%), cough $(60 \%)$, rashes $(41.5 \%)$ and diarrhoea (15.8\%). (Table 3)

On general examination 384(41.5\%) patients had icterus while pallor was present in 206(22.2\%) patients. 504(54.4\%) cases were found to have hepatosplenomegaly. Although 410(44.3\%) cases had added breath sounds.(Table 4)

On further hematological and biochemical workup, $626(67.6 \%)$ cases had leukocytosis while $184(19.9 \%)$ cases had leucopenia. 402 (43.4\%) patients have thrombocytopenia. (Table 5)

$516(55.7 \%)$ cases were found to have elevated bilirubin while deranged SGOT, SGPT and RFT were found in 480(51.8\%), 386(41.7\%) and $204(22 \%)$ cases respectively. (Table 6)

Among these 926 study participants, etiologically $13.6 \%$ were diagnosed as Malaria, $15.2 \%$ as typhoid, $9.2 \%$ as dengue, $20.1 \%$ as Rickettsial Fever, $8.7 \%$ as Urinary tract infections and $8.4 \%$ remains undiagnosed. (Table 7).

History of hypertension, diabetes, cardiovascular diseases and COPDs was asked. These all comorbidities, combined together were present in $9.1 \%$ of patients.

Average length of stay for majority was between 3 to 5 days with mean length of stay was 4.36 days.

Table 1 Sex Distribution

\begin{tabular}{|l|c|c|}
\hline Sex & Number Of Patients (N) & Percentage (\%) \\
\hline Male & 540 & 58.3 \\
\hline Female & 386 & 41.7 \\
\hline Total & 926 & 100 \\
\hline
\end{tabular}

Table 2- Age Distribution

\begin{tabular}{|l|c|c|}
\hline Age( In Yrs) & $\begin{array}{c}\text { Number Of Patients } \\
(\mathrm{n})\end{array}$ & $\begin{array}{c}\text { Percentage } \\
(\%)\end{array}$ \\
\hline $15-25$ & 164 & 17.7 \\
\hline $26-35$ & 174 & 18.8 \\
\hline $36-45$ & 198 & 21.4 \\
\hline $46-55$ & 126 & 13.6 \\
\hline $56-65$ & 78 & 8.4 \\
\hline $66-75$ & 74 & 8 \\
\hline $76-85$ & 86 & 9.3 \\
\hline$>86$ & 26 & 2.8 \\
\hline Total & 926 & 100 \\
\hline
\end{tabular}


Table 3-Associated Symptoms with Fever

\begin{tabular}{|l|c|c|}
\hline Symptoms & $\begin{array}{c}\text { Number Of } \\
\text { Patients (n) }\end{array}$ & $\begin{array}{c}\text { Percentage } \\
(\%)\end{array}$ \\
\hline Cough & 246 & 60 \\
\hline Rash & 384 & 41.5 \\
\hline Burning Micturation & 216 & 23.3 \\
\hline Diarrhoea & 146 & 15.8 \\
\hline Rigor And Chills & 410 & 44.3 \\
\hline Malaise & 580 & 62.6 \\
\hline Joint Pains & 284 & 30.7 \\
\hline Chest Pain & 136 & 14.7 \\
Breathlessness & 190 & 20.5 \\
\hline Pain Abdomen & 289 & 31.2 \\
\hline Vomiting & 410 & 44.3 \\
\hline
\end{tabular}

Table 4 Clinical Signs in Patients

\begin{tabular}{|l|c|c|}
\hline Clinical Signs & $\begin{array}{c}\text { Number of Patients } \\
(\mathrm{n})\end{array}$ & $\begin{array}{c}\text { Percentage } \\
(\%)\end{array}$ \\
\hline Pallor & 206 & 22.2 \\
\hline Icterus & 384 & 41.5 \\
\hline Hepato-Splenomegaly & 504 & 54.4 \\
\hline Added Breath Sounds & 410 & 44.3 \\
\hline Pedal Edema & 126 & 13.6 \\
\hline Neck Stiffness & & \\
\hline Renal Tenderness & 56 & 6.04 \\
\hline
\end{tabular}

Table 5 Hematological Finding

\begin{tabular}{|l|c|c|}
\hline Hematological Finding & $\begin{array}{c}\text { Number of } \\
\text { Patients }(\mathrm{n})\end{array}$ & $\begin{array}{c}\text { Percentage } \\
(\%)\end{array}$ \\
\hline Leucocytosis $(>11000 /$ cumm $)$ & 626 & 67.6 \\
\hline Leucopenia (<4000/cumm) & 184 & 19.9 \\
\hline $\begin{array}{l}\text { Thrombocytopenia } \\
(<1.5 \mathrm{LAC} / \text { cumm})\end{array}$ & 402 & 43.4 \\
\hline Abnormal PTI & 101 & 10.9 \\
\hline
\end{tabular}

Table 6 Patients with Abnormal LFT and KFT

\begin{tabular}{|l|c|c|}
\hline Parameter & $\begin{array}{c}\text { Number of } \\
\text { Patients (n) }\end{array}$ & $\begin{array}{c}\text { Percentage } \\
(\%)\end{array}$ \\
\hline Raised Sgot & 480 & 51.8 \\
\hline Raised Sgpt & 386 & 41.7 \\
\hline Raised Bilirubin & 516 & 55.7 \\
\hline $\begin{array}{l}\text { Raised S.Urea Or } \\
\text { Creatinine }\end{array}$ & 204 & 22 \\
\hline
\end{tabular}

Table 7 Different Tropical Infections/Etiology of Fever Detected in the Study

\begin{tabular}{|l|c|c|}
\hline Etiology & $\begin{array}{c}\text { Number Of } \\
\text { Patients (N) }\end{array}$ & $\begin{array}{c}\text { Percentage } \\
(\%)\end{array}$ \\
\hline Enteric Fever & 140 & 15.2 \\
\hline Dengue & 85 & 9.2 \\
\hline Malaria & 126 & 13.6 \\
\hline Pneumonia & 86 & 9.4 \\
\hline UTI & 81 & 8.7 \\
\hline Meningo-Encephalitis & & \\
\hline Rickettsial Fever & 186 & 20.1 \\
\hline
\end{tabular}

\begin{tabular}{|l|c|c|}
\hline Hepatitis A & 28 & 3 \\
\hline Hepatitis E & 26 & 2.8 \\
\hline Varicella & 14 & 1.5 \\
\hline Drug Fever & 18 & 1.9 \\
\hline $\begin{array}{l}\text { Undifferentiated Viral } \\
\text { Fever }\end{array}$ & 78 & 8.4 \\
\hline Liver Abscess & 45 & 4.9 \\
\hline HIV & 5 & 0.5 \\
\hline Leptospirosis & 2 & 0.2 \\
\hline
\end{tabular}

\section{Discussion}

Our study showed high incidence of tropical infections such as Clinical Enteric fever, Dengue, Malaria, Varicella, UTI and hepatitis A and E with most common infection in our area as Rickettsial Fever. In our study 85(9.2\%) cases were diagnosed as dengue fever.

It is useful to remember that geriatric age group with UTI or pneumonia often present with febrile encephalopathy with few other clinical signs. In our study $86(9.4 \%)$ cases had pneumonia (clinicradiologically proven). 186 patients presented with rickettsial disease .The disease occurs 7-10 days after the bite of larval from of trombiculid mite and present with fever, relative bradycardia, severe myalgias and a non-pruritic macularpapular rash. Splenomegaly was detected in 44 to $52 \%$ of the cases described in the recent outbreaks in the Shimla hills while the characteristic eschar was seen only in a minority of cases $(9.5 \%)^{[10,11]}$. Both of our cases had characteristic eschar formation with splenomegaly and serositis. Clinical jaundice and deranged LFTs have been described in outbreaks of scrub typhus seen in Shimla hills with a reported incidence of jaundice in $10-52 \%$ and elevated AST/ALT in 28 to $67 \%$ cases.

Malaria positive cases and enteric cases were found $13.6 \%$ and $15.2 \%$ respectivlely in present study which was comparable to a study done by Balvinder et al in which was reported $4.7 \%$. \& $10.9 \%$ respectively. ${ }^{[12]}$ Comorbidities like HTN, DM2, CAD, COPD combined together were present in $9.1 \%$ of patients in these studies. Low incidence of comorbidity may be explained by relatively younger people getting affected from the illness, as these comorbidities are usually associated with the advanced age. Most common 
age group affected in this study was between 15 45 years of age, reflecting young economically active people are affected more with these illnesses which were also supported by literature. ${ }^{[13,14]}$ Increased outdoor exposure to mosquitoes and ticks, use of contaminated water may be factor responsible for this. Males predominate over female in this study. Similar observation was made by other study conducted in northern India. ${ }^{[15]}$ It can also be explained with more outdoor activities and more risk of exposure for mosquito bite among males.

Present epidemiological evidence of association of comorbidities with severity of illness is limited and only suggestive. However it is important to identify these comorbidities early and patient should be kept in close observation if needed to improve outcome and avoid complications. ${ }^{[16]}$

\section{Limitation of Study}

- The limitation of our study is that it excluded the paediatrics age group or else we could have expected to have different fever etiology due to exposure and immunity. Hence, it is prudent that the pattern of fever etiology found in our study is not representative of general population.

- Data to differentiate vivax from falciparum and serial platelet counts could not be collected in this study. Enteric fever cases would have been diagnosed better if tests for blood culture and Widal test data could have been correlated. Though sensitivity and specificity of the serological testing for various aetiologies are not $100 \%$ and chances of over or under diagnosis is there. However, this number should not be large enough to interfere with the purpose of the study

\section{Conclusion}

In our study, predominantly young population ( $<55$ years $)$ was most commonly affected .The most common etiology was found to be Rickettsial Fever followed by Enteric Fever and Malaria. This upholds the necessity for better health awareness, early transport and presentation along with better diagnostic tools at primary health care facilities. A protocol based approach for diagnosing and managing Acute Febrile illness should be done to reduce the cost, burden on healthcare system.

Declaration of Conflicts of Interest- All authors have none to declare.

\section{References}

1. Blumberg L, Ogunbanjo GA, Durrheim DN. Fever in adults-approach to diagnosis and management, SA Fam Pract .2000; 22:23-26.

2. Joshi R, Colford JM, Reingold A. Nonmalarial acute undifferentiated fever in a rural hospital in central India Diagnostic uncertainty and overtreatment with antimalarial agents. Am J Trop Med Hyg. 2008;78(3):393-99.

3. Chrispal A, Boorugu $\mathrm{H}$, Gopinath KG, Chandy S, PrakashJA,et al. Acute undifferentiated febrile illness in India. Int Journal of Emer Med. 2011;4:57.

4. Chrispal A, Boorugu H, Gopinath KG, Chandy S, Prakash JA, et al. Acute Undifferentiated febrile illness in adult hospitalized patients: the disease spectrum and diagnostic predictors - an experience from a tertiary care hospital in South India. Trop Doc. 2010;40(4):230-34.

5. Garima Mittal, Sohaib Ahmad, R K Agarwal, Minakshi Dhar, Manish Mittal, et al . Aetiologies of Acute Undifferentiated Febrile illness in Adult Patients - an Experience from a Tertiary Care Hospital in Northern India Journal of Clinical and Diagnostic Research. 2015 Dec, Vol-9(12): DC22-4.

6. Singh R, Singh SP, Ahmad N. A Study of Etiological Pattern in an Epidemic of Acute Febrile Illness during Monsoon in a Tertiary Health Care Institute of 
Uttarakhand, India. J ClinDiagn Res. 2014;8(6):MC01-03.

7. Susilawati, T.N., et al. Acute undifferentiated fever in Asia: a review of the literature. The Southeast Asian J. Trop. Med. Public Health.2014, 45(3): 71926.

8. Manocha, et al. Frequency of leptospirosis in patients of acute febrile illness in Uttar Pradesh. 2004J. Assoc. Physicians of India, 52: 623-5.

9. Phuong, H.L., et al. Acute undifferentiated fever in Binh Thuan Province, Vietnam: Imprecise clinical diagnosis and irrational pharmacotherapy 2006. Trop. Med. Int. Health, 11: 869-79

10. Sharma A, Raina R, Dhiman P, Adarsh, Madhabhavi I, Panda P. Rare Coinfection of Scrub Typhus and Malaria in Immunocompetent Person. Online J Health Allied Scs. 2012;11(2):12.

11. Shashidharan VK, Nagpal AK. Tropical infections in ICU. In: Handbook of Medical Emergencies, 2nd Edition, India: Department of Internal Medicine, AFMC Pune; 2015. 306-19.

12. Balvinder Singh Arora, Monika Matlani, Karnika Saigal. Major aetiologies of acute undifferentiated fever in 2013 and 2014: an experience in retrospect Int J Adv Med. 2017 Apr; 4(2):568-572

13. Sharma A, Raina R, Dhiman P, Adarsh, Madhabhavi I, Panda P. Rare Coinfection of Scrub Typhus and Malaria in Immunocompetent Person. Online J Health Allied Scs. 2012; 11(2):12

14. MA Andrews, Aleena Elizabeth, Praveenlal Kuttichira. Clinical profile of acute undifferentiated febrile illness in patients admitted to a teaching hospital in Kerala. Health Sciences 2014;1(3): JS001D.
15. Garima Mittal, Sohaib Ahmad, R K Agarwal, Minakshi Dhar, Manish Mittal, and Shiwani Sharma. Aetiologies of Acute Undifferentiated Febrile illness in Adult Patients - an Experience from a Tertiary Care Hospital in Northern India. J ClinDiagn Res. 2015 Dec; 9(12): 22-24

16. Pang J, Salim A, Lee VJ, Hibberd ML, Chia KS, Leo YS, et al. Diabetes with hypertension as risk factors for adult dengue haemorrhagic fever in a predominantly dengue serotype 2 epidemic: a case control study. PLoSNeglTrop Dis. 2012; 6(5):e1641. 